\title{
Article
}

\section{Anatomical Risk Factors of Inferior Alveolar Nerve Injury Association with Surgical Extraction of Mandibular Third Molar in Korean Population}

\author{
Hee Jin Kim ${ }^{1}$, Ye Joon Jo ${ }^{1}$, Jun Seok Choi ${ }^{1}$, Hyo Joon Kim ${ }^{2}$, Jin Kim ${ }^{2}$ and Seong Yong Moon $2, * \mathbb{C}$ \\ 1 Department of Oral and Maxillofacial Surgery, Chosun University Dental Hospital, Gwangju 61452, Korea; \\ maje7394@naver.com (H.J.K.); jyj4677@gmail.com (Y.J.J.); godflyword@naver.com (J.S.C.) \\ 2 Department of Oral and Maxillofacial Surgery, College of Dentistry, Chosun University, Gwangju 61452, \\ Korea; rfa21@naver.com (H.J.K.); cream4251@hanmail.net (J.K.) \\ * Correspondence: msygood@chosun.ac.kr
}

check for updates

Citation: Kim, H.J.; Jo, Y.J.; Choi, J.S.; Kim, H.J.; Kim, J.; Moon, S.Y.

Anatomical Risk Factors of Inferior Alveolar Nerve Injury Association with Surgical Extraction of Mandibular Third Molar in Korean Population. Appl. Sci. 2021, 11, 816. https://doi.org/10.3390/ app11020816

Received: 17 December 2020

Accepted: 12 January 2021

Published: 16 January 2021

Publisher's Note: MDPI stays neutral with regard to jurisdictional claims in published maps and institutional affiliations.

Copyright: (c) 2021 by the authors. Licensee MDPI, Basel, Switzerland. This article is an open access article distributed under the terms and conditions of the Creative Commons Attribution (CC BY) license (https:// creativecommons.org/licenses/by/ $4.0 /)$.

\begin{abstract}
The purpose of this study was to analyze the incidence and risk factors of possible inferior alveolar nerve (IAN) injury after extraction of the mandibular third molars. A total of 6182 patients were examined for 10,310 mandibular third molar teeth. Panoramic radiography and patients' medical records were used to analyze age, gender, and impaction pattern of the mandibular third molar. Cone beam computed tomography (CBCT) was used to investigate the detailed pathway of the inferior alveolar nerve and evaluated the presence of symptoms of nerve damage after tooth extraction. In CBCT, 6283 cases $(61 \%)$ of the inferior alveolar nerve were actually in contact with the root of the mandibular third molar. The correlation with the panoramic signs of root darkening $(p<0.001)$, root deflection $(p<0.001)$, interruption of the IAN $(p<0.001)$, diversion of the IAN $(p<0.001)$, and narrowing of the IAN $(p<0.001)$ had statistical significance. Of the 4708 patients who underwent surgical extraction, $31(0.658 \%)$ complained of nerve damage. Among them, 30 patients $(0.637 \%)$ complained of symptoms of inferior alveolar nerve damage, and 1 patient $(0.02 \%)$ complained of symptoms of lingual nerve damage. There was a significant correlation with IAN injury in cases where the roots became dark at the IAN area $(p=0.018)$ and there was diversion of the IAN at the root area $(p=0.041)$. When the narrowing of the IAN and the lingual driving pathway of the inferior alveolar nerve appeared simultaneously in CBCT, the risk of IAN injury was high.
\end{abstract}

Keywords: third molar; inferior alveolar nerve; third molar extraction; impacted mandibular third molar; CBCT

\section{Introduction}

The third molar is the most commonly impacted tooth. Several causes can lead to impaction of the mandibular third molars. Eruption can be interfered by local physical barriers such as adjacent teeth, dense bones, excessive soft tissue, and lesions [1]. The prevalence of impacted third molars has been reported in the range of $30.3 \%$ to $68.6 \%$ [2-6]. The extraction of the mandibular third molar is one of the most common surgeries in oral and maxillofacial surgery [7,8]. Complications that can occur when extracting the mandibular third molar include damage to the adjacent teeth, swelling, bleeding, infection, and nerve damage. Among the potential complications associated with removal of the third molar, inferior alveolar nerve (IAN) injury is a representative complication. Several studies have reported an incidence of IAN injury of $0.26-8.4 \%$ [9-15]. Various factors such as the age of the patient, the experience of the surgeon, and the extent and location of the impaction are discussed as the risk factors of the nerve injury [15-17].

The most important risk factor for IAN injury is the correlation between the anatomical position of the third molar and the proximity of the IAN [12,18]. Panoramic radiographs are widely used for initial examination to assess the third molar. However, it is not possible to 
accurately determine the buccal and lingual positioning of the third molar and nerves on a two-dimensional panoramic radiograph. Therefore, it is not easy to assess the possibility of nerve injury from panoramic radiographs [19]. There have been many studies regarding the correlation between the mandibular third molar and the IAN, and the signs that can predict the possibility of IAN injury using a two-dimensional panoramic radiograph [20]. Previous studies have reported a correlation between some panoramic signals and nerve injury, but the results are not unified [21-30]. In order to overcome the limitations of panoramic radiographs, the use of cone beam computed tomography (CBCT) has recently increased. CBCT is very useful for the evaluation of impacted mandibular third molars [31] and the proximity of the IAN, and to improve the risk assessment prior to surgery [32].

Panoramic signals of IAN contacts have shown frequently, however, the occurrence of IAN injury is rare and it is very hard to predict nerve injury. The purpose of this study was to analyze the incidence and risk factors of possible IAN injury after extraction of the mandibular third molars. CBCT and panoramic radiography was used to evaluate the factors that may have affected inferior alveolar nerve injury.

\section{Patients and Methods}

This study was conducted with the approval of the Institutional Review Board (IRB) (CUDHIRB 1902 006) from $1^{\text {st }}$ Jan 2016 to $31^{\text {th }}$ Mar 2020 in patients who presented with a mandibular third molar. They underwent panoramic radiography as well as $\mathrm{CBCT}$. The CBCT used an Aquilion ONE CT system (Aquilion One, Canon Medical Systems, Otawara, Japan). The scanning conditions were as follows: Tube images demonstrated an expansile lesion obstructing the entire left maxillary sinus just below the current $250 \mathrm{~mA}$, tube potential was $120 \mathrm{kV}$, scanning time was $0.5 \mathrm{~s} / \mathrm{scan}$, and slice thickness was $0.5 \mathrm{~mm}$. Patients with alveolar bone pathologies, craniofacial deformities such as Down syndrome or cleidocranial dysplasia, and cases with low quality panoramic radiography and CBCT were excluded. A total of 6182 patients were examined out of 10,310 patients with mandibular third molar teeth.

\subsection{The Impaction Pattern of the Mandibular Third Molar}

The panoramic radiography and patients' medical records were used to analyze age, gender, and the impaction pattern of the mandibular third molar. In this study, two main classification criteria were applied to determine the impaction pattern of the mandibular third molars.

\subsubsection{Pell and Gregory Classification}

According to the Pell and Gregory classification [33], the impacted mandibular third molars were classified into three stages according to the depth of impaction with regards to the adjacent teeth: (1) Class A, when the highest point of the occlusal surface of the impacted mandibular third molar is at the same height as the occlusal surface of the adjacent tooth; (2) Class B, when the highest point of the occlusal surface of the impacted mandibular third molar is between the occlusal surface of the adjacent tooth and the cervical line; and (3) Class $\mathrm{C}$, when the highest point of the occlusal surface of the impacted mandibular third molar is below the cervical line of the adjacent tooth. In addition, Classes I, II, and III were classified by the distance between the anterior margin of the ascending mandibular ramus and the distal surface of the mandibular second molars: (4) Class I, when the distance from the anterior margin of the ascending mandibular ramus to the distal surface of the mandibular second molar is wider than the width of the occlusal surface of the impacted mandibular third molar; (5) Class II, when the distance from the anterior margin of the ascending mandibular ramus to the distal surface of the mandibular second molar is narrower than the width of the occlusal surface of the impacted mandibular third molar and wider than $1 / 2$; and (6) Class III, when the distance from the anterior margin of the ascending mandibular ramus to the distal surface of the mandibular second molar is narrower than the width of the occlusal surface of the impacted mandibular third molar (Figure 1). 


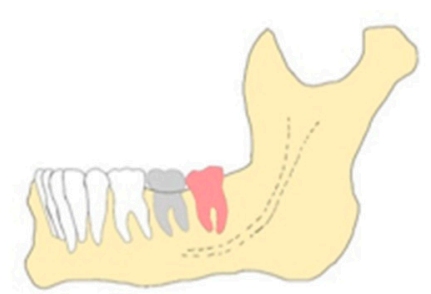

A

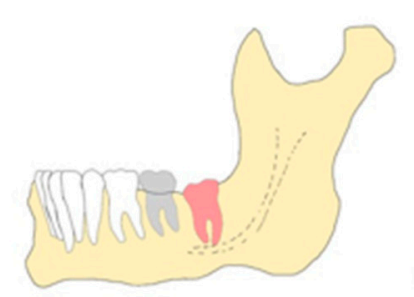

D

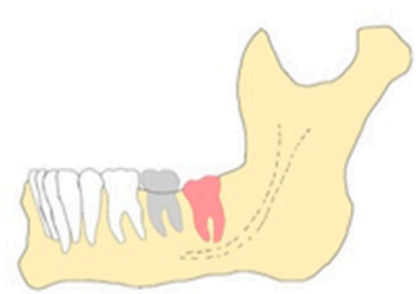

B

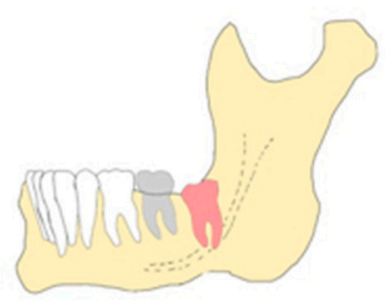

E

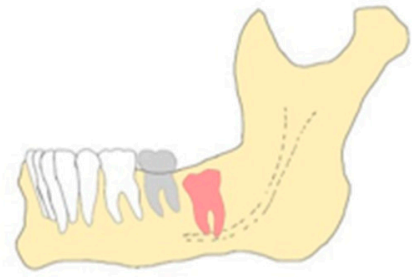

C

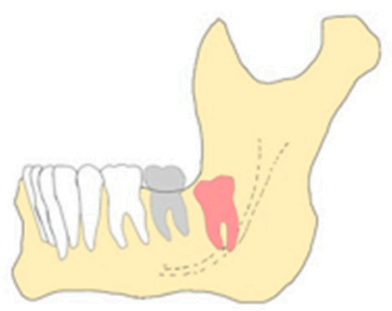

F

Figure 1. Pell and Gregory classification: (A) Class A, (B) Class B, (C) Class C, (D) Class I, (E) Class II, and (F) Class III.

\subsubsection{Winter's Classification}

Winter's classification is based on the angle of impaction of the mandibular third molar [34]. The reference angle is the angle to the long axis of the mandibular second molars. It was classified into vertical $\left(10^{\circ}--10^{\circ}\right)$, mesioangular $\left(11^{\circ}-79^{\circ}\right)$, horizontal $\left(80^{\circ}-100^{\circ}\right)$, distoangular $\left(-11^{\circ}--79^{\circ}\right)$, transverse (buccal-lingual), and inverted $\left(101^{\circ}--80^{\circ}\right)$ (Figure 2).

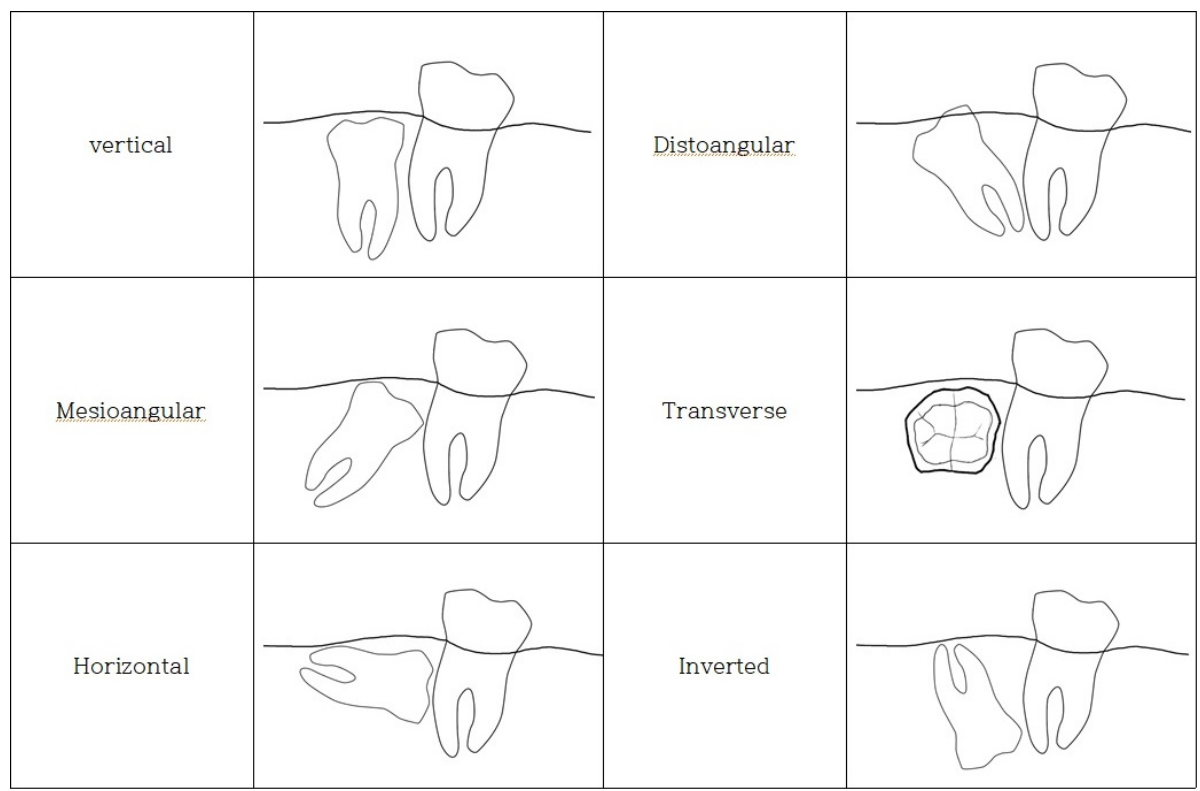

Figure 2. Winter's classification.

\subsection{Panoramic Radiograph}

The relationship between the IAN and the mandibular third molar root was observed on panoramic radiography. Based on seven radiographic signs suggested by Rood and Shehab [20], darkening and bifid of the root apex at the IAN area was included as the case of darkening of the root because it was not easy to distinguish. In addition, there were cases where the dark line is visible at the root apex, and this case was also investigated. The radiographic signs were divided into a total of seven observations (Figures 3 and 4): 
(1) cases where the root was darkened in the IAN area, (2) cases where the root was curved at the IAN area, (3) cases where the root was narrowed in the IAN area, (4) cases with a dark line at the root apex, (5) cases with the loss of the white line of the IAN at the root area, (6) cases with a narrowed IAN at the root area, and (7) cases with a change in the pathway of the IAN at the root area.
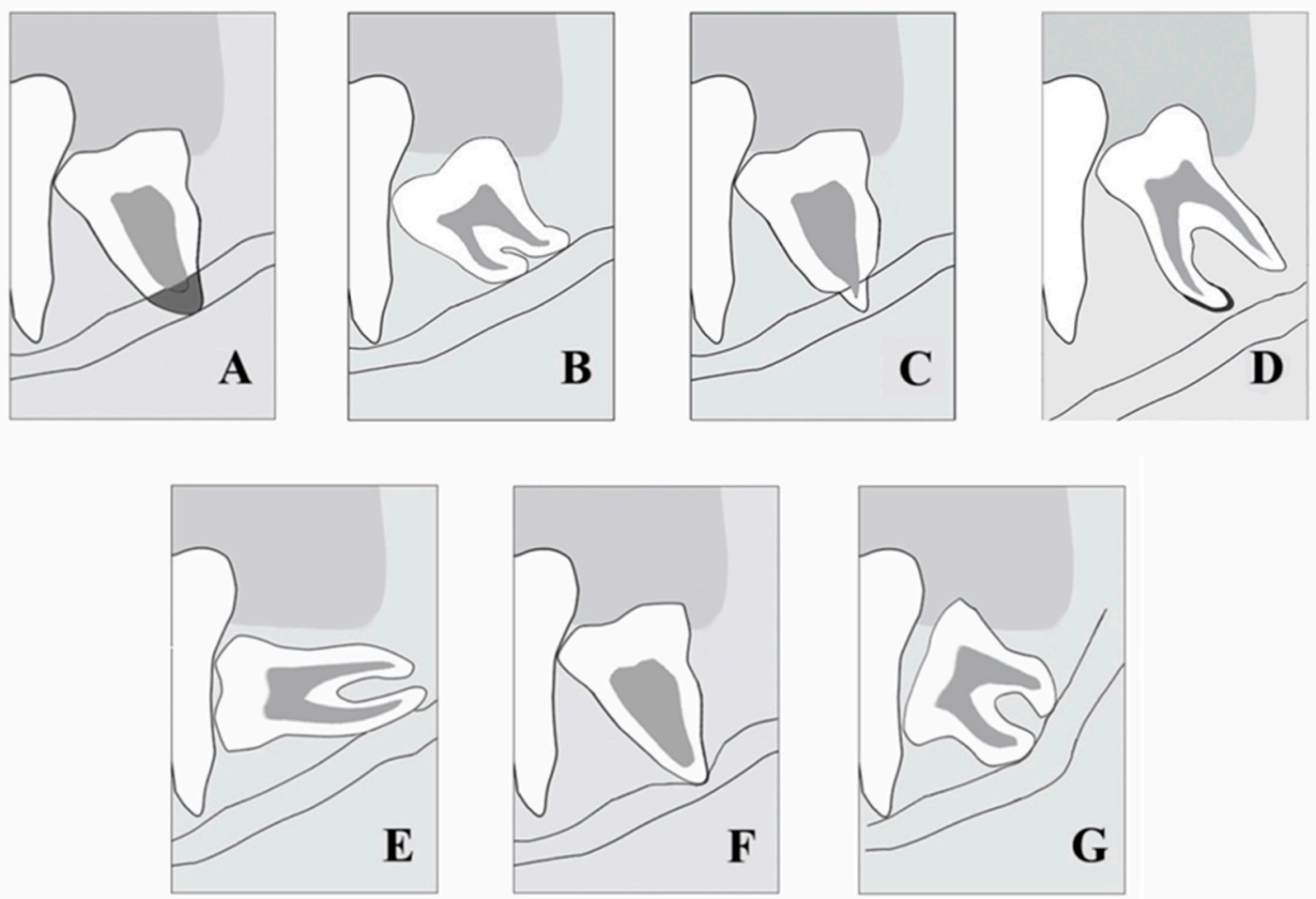

Figure 3. Rood and Shehab classification of radiographic signs: (A) root darkening, (B) root deflection, (C) root narrowing, (D) dark line in apex, (E) loss of white line, (F) inferior alveolar nerve (IAN) narrowing, and (G) IAN diversion.
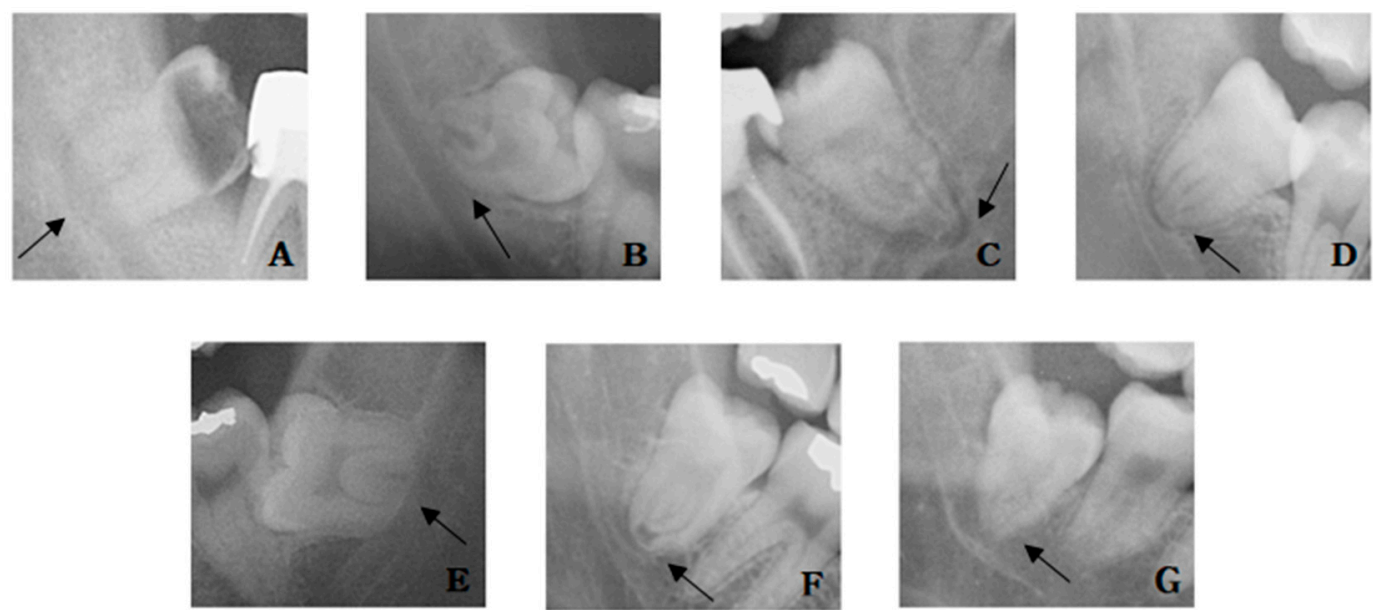

Figure 4. Panoramic view. Arrows indicated the panoramic signs: (A) root darkening, (B) root deflection, (C) root narrowing, (D) dark line in apex, (E) loss of white line, (F) inferior alveolar nerve (IAN) narrowing, and (G) IAN diversion.

\subsection{CBCT Analysis}

The positional relationship between the root of the mandibular third molar and the inferior alveolar nerve was analyzed. In the panoramic radiograph, the root of the mandibular third molar and the inferior alveolar nerve overlapped, but CBCT was observed to see if they 
were actually in contact with each other, and whether they were on the buccal side, on the lingual side, below the root, or between the root if not on the bucco-lingual side (Figure 5). In addition, the relationship between the root of the mandibular third molar and the lingual cortical bone was also observed. If continuity of the lingual cortical bone was lost due to the root, it was classified as cortical bone perforation. Finally, patients who complained of nerve injury after surgical extraction were investigated using medical records.
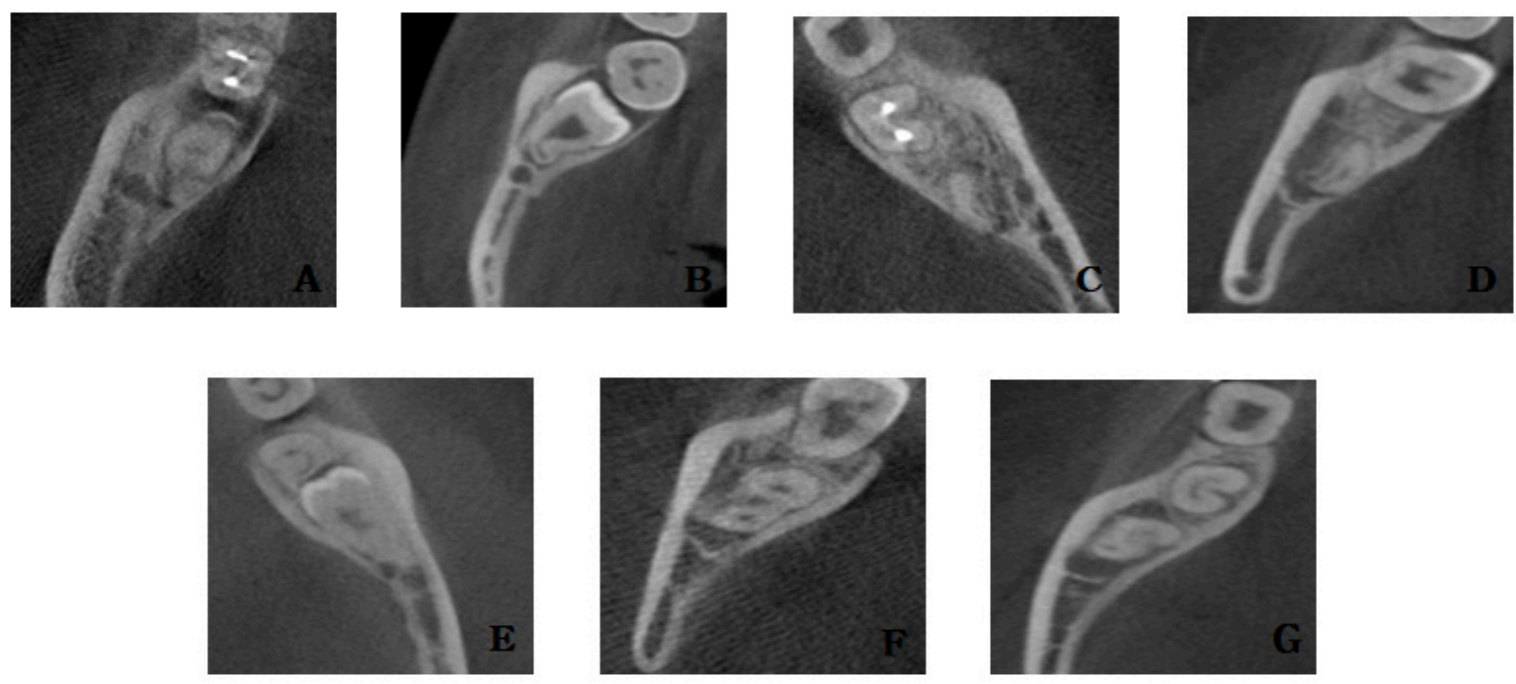

Figure 5. Relationship between the inferior alveolar canal and roots in cone beam computer tomography views: (A) root darkening in panoramic view, (B) root deflection in panoramic view, (C) root narrowing in panoramic view, (D) dark line in apex in panoramic view, (E) loss of white line in panoramic view, (F) inferior alveolar nerve (IAN) narrowing in panoramic view, and (G) IAN diversion in panoramic view.

\subsection{Statistical Analysis}

Statistical analysis of this study was performed using the SPSS 20.0 (SPSS Software, Chicago, IL, USA) statistical program. The frequency and percentage of each category was calculated, and the chi-square test was performed for categorical variables. The correction odds ratio was obtained for each category and verified and analyzed at the significance level $p<0.05$.

\section{Results}

\subsection{Distributions of Gender and Age}

The average age was 33.5 years, and 10 - to 39 -year-olds accounted for $88.4 \%$. The age distribution was $16.6 \%, 56.9 \%$, and $14.9 \%$ in the second, third, and fourth decades of life, respectively (Table 1). A total of 4708 of 6182 people underwent third molar extraction; men were $52.1 \%$ and $47.9 \%$ were women.

\subsection{Impaction Patterns}

Horizontal impaction (42.1\%) was the most common, followed by mesial impaction $(29.8 \%)$, vertical impaction (22.9\%), inverted impaction (2.7\%), distoangular impaction $(1.5 \%)$, and bucco-lingual transverse impaction (0.9\%) (Figure 6).

\subsection{Impaction Depth}

In the Pell and Gregory classification, class A (53.4\%) was the most common, followed by class B (34\%), and class C (12.6\%). For Class I, II, and III classification, Class II (55.3\%) was the most common, followed by Class III (33.0\%) and Class I (11.7\%). When the two categories were combined and confirmed, Class IIA ( $30 \%)$ occupied the largest proportion, followed by Class IIB (19\%), Class IIIA (16\%), and Class IIIB (12\%) (Table 2). 
Table 1. Distributions of gender and age.

\begin{tabular}{cccc}
\hline & & No. & $\%$ \\
\hline Total & & 6182 & 100.0 \\
\hline \multirow{2}{*}{ Gender } & Male & 3220 & 52.1 \\
& Female & 2962 & 47.9 \\
\hline \multirow{2}{*}{ Age } & $10-19$ & 1026 & 16.6 \\
& $20-29$ & 3518 & 56.9 \\
& $30-39$ & 921 & 14.9 \\
& $40-49$ & 436 & 7.1 \\
& $50-59$ & 178 & 2.9 \\
& $60-69$ & 75 & 1.2 \\
\hline
\end{tabular}

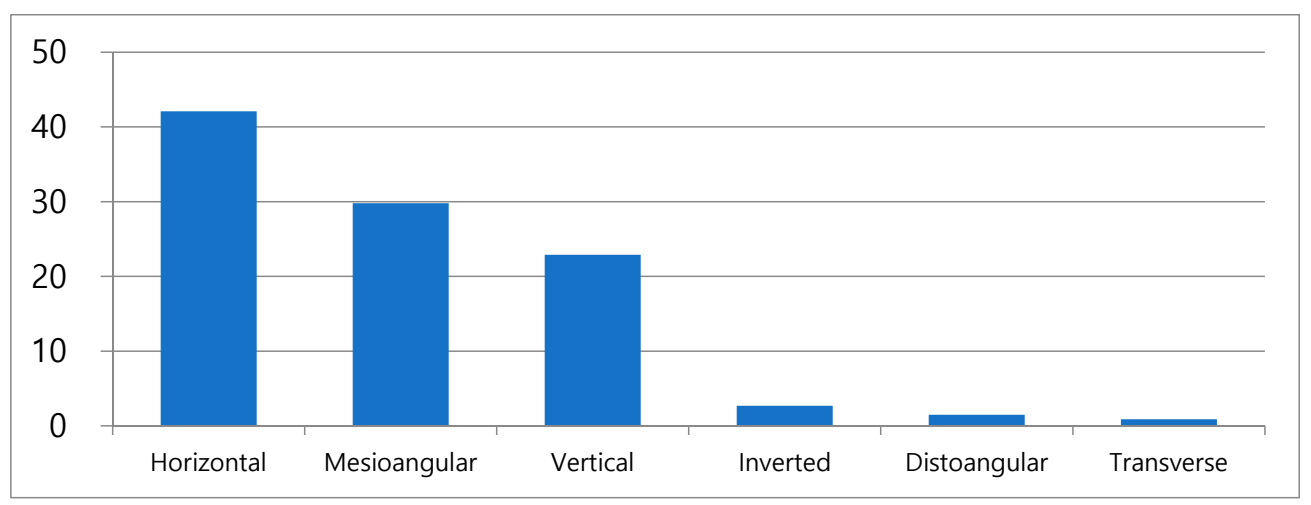

Figure 6. Distribution of the Winter classification: horizontal impaction (42.1\%), mesioangular impaction (29.8\%), vertical impaction (22.9\%), inverted impaction (2.7\%), distoangular impaction (1.5\%), and transverse impaction (0.9\%).

Table 2. Distribution of the Pell and Gregory classification.

\begin{tabular}{cccc}
\hline & & No. & \% \\
\hline Total & & 10,310 & 100.0 \\
\hline \multirow{2}{*}{ P.G. A, B, C } & A & 5509 & 53.4 \\
& B & 3503 & 34.0 \\
P.G. I, II, III & C & 1298 & 12.6 \\
& I & 1204 & 11.7 \\
& II & 5704 & 55.3 \\
P.G. A, B, C and I, II, III & III & 3402 & 33.0 \\
& IA & 756 & 7.3 \\
& IB & 320 & 3.1 \\
& IC & 128 & 1.2 \\
& IIA & 3088 & 30.0 \\
& IIB & 1990 & 6.1 \\
& IIC & 626 & 16.1 \\
& IIIA & 1665 & 11.6 \\
& IIIB & 1193 & 5.3 \\
\hline
\end{tabular}

Age and Pell and Gregory classification (P.G.) showed a statistically significant correlation as a result of Pearson's chi-square test, with a significance less than 0.05 (Table 3). 
Table 3. Age distribution of the Pell and Gregory classification.

\begin{tabular}{|c|c|c|c|c|c|c|c|c|c|c|c|}
\hline Age & A (\%) & B (\%) & C (\%) & Total (\%) & $p$ Value & Age & I (\%) & II (\%) & III (\%) & Total (\%) & $p$ Value \\
\hline 10-19 & $\begin{array}{c}1243 \\
(66.2)\end{array}$ & $\begin{array}{c}459 \\
(24.4)\end{array}$ & $\begin{array}{c}177 \\
(9.4)\end{array}$ & $\begin{array}{c}1879 \\
(100.0)\end{array}$ & & 10-19 & $\begin{array}{c}173 \\
(9.2)\end{array}$ & $\begin{array}{c}1034 \\
(55.0)\end{array}$ & $\begin{array}{c}672 \\
(35.8)\end{array}$ & $\begin{array}{c}1879 \\
(100.0)\end{array}$ & \\
\hline $20-29$ & $\begin{array}{c}3424 \\
(56.5)\end{array}$ & $\begin{array}{c}2157 \\
(35.6)\end{array}$ & $\begin{array}{c}481 \\
(7.9)\end{array}$ & $\begin{array}{c}6062 \\
(100.0)\end{array}$ & & $20-29$ & $\begin{array}{c}646 \\
(10.7)\end{array}$ & $\begin{array}{c}3395 \\
(56.0)\end{array}$ & $\begin{array}{c}2021 \\
(33.3)\end{array}$ & $\begin{array}{c}6062 \\
(100.0)\end{array}$ & \\
\hline 30-39 & $\begin{array}{c}554 \\
(39.8)\end{array}$ & $\begin{array}{c}549 \\
(39.4)\end{array}$ & $\begin{array}{c}290 \\
(20.8)\end{array}$ & $\begin{array}{c}1393 \\
(100.0)\end{array}$ & & $30-39$ & $\begin{array}{c}177 \\
(12.7)\end{array}$ & $\begin{array}{c}773 \\
(55.5)\end{array}$ & $\begin{array}{c}44 . \\
(31.8)\end{array}$ & $\begin{array}{c}1393 \\
(100.0)\end{array}$ & \\
\hline $40-49$ & $\begin{array}{c}174 \\
(28.1)\end{array}$ & $\begin{array}{c}242 \\
(39.0)\end{array}$ & $\begin{array}{c}204 \\
(32.9)\end{array}$ & $\begin{array}{c}620 \\
(100.0)\end{array}$ & $p<0.001 *$ & $40-49$ & $\begin{array}{c}103 \\
(16.6)\end{array}$ & $\begin{array}{c}345 \\
(55.6)\end{array}$ & $\begin{array}{c}172 \\
(27.7)\end{array}$ & $\begin{array}{c}620 \\
(100.0)\end{array}$ & $p<0.001 *$ \\
\hline $50-59$ & $\begin{array}{c}66 \\
(29.3)\end{array}$ & $\begin{array}{c}63 \\
(28.0)\end{array}$ & $\begin{array}{c}96 \\
(42.7)\end{array}$ & $\begin{array}{c}225 \\
(100.0)\end{array}$ & & $50-59$ & $\begin{array}{c}50 \\
(22.2)\end{array}$ & $\begin{array}{c}107 \\
(47.6)\end{array}$ & $\begin{array}{c}68 \\
(30.2)\end{array}$ & $\begin{array}{c}225 \\
(100.0)\end{array}$ & \\
\hline $60-69$ & $\begin{array}{c}39 \\
(39.8)\end{array}$ & $\begin{array}{c}27 \\
(27.6)\end{array}$ & $\begin{array}{c}32 \\
(32.7)\end{array}$ & $33(100.0)$ & & $60-69$ & $\begin{array}{c}40 \\
(40.8)\end{array}$ & $\begin{array}{c}36 \\
(36.7)\end{array}$ & $\begin{array}{c}22 \\
(22.4)\end{array}$ & $33(100.0)$ & \\
\hline 70-79 & $\begin{array}{c}9 \\
(27.3)\end{array}$ & $\begin{array}{c}6 \\
(18.1)\end{array}$ & $\begin{array}{c}18 \\
(54.5)\end{array}$ & $33(100.0)$ & & $70-79$ & $\begin{array}{c}15 \\
(54.5)\end{array}$ & $\begin{array}{c}14 \\
(42.4)\end{array}$ & $4(12.1)$ & $33(100.0)$ & \\
\hline Total & $\begin{array}{c}5509 \\
(53.4)\end{array}$ & $\begin{array}{c}3503 \\
(34.0)\end{array}$ & $\begin{array}{c}1298 \\
(12.6)\end{array}$ & $\begin{array}{c}10,310 \\
(100.0)\end{array}$ & & Total & $\begin{array}{c}1204 \\
(11.7)\end{array}$ & $\begin{array}{c}5704 \\
(55.3)\end{array}$ & $\begin{array}{c}3402 \\
(33.0)\end{array}$ & $\begin{array}{l}10,310 \\
(100.0)\end{array}$ & \\
\hline
\end{tabular}

* Statistical significance $p<0.05$, Pearson's chi-square test.

\subsection{Relationship between the IAN and the Mandibular Third Molar in Panorama}

A total of $88.7 \%$ were in contact with the IAN in panoramic view. As for the signs that could infer the relationship between the IAN and the mandibular third molar, root darkening cases $(30.2 \%)$ of the IAN region showed the largest number, and the second was the interruption of the IAN (24.7\%) where the white line of the inferior alveolar nerve canal was absent from the teeth, followed by a dark line of the root $(16.2 \%)$, deflection of the root $(9.6 \%)$, diversion of the IAN (5.1\%) root narrowing (5.0\%), and narrowing of the IAN (3.7\%) (Figure 7).

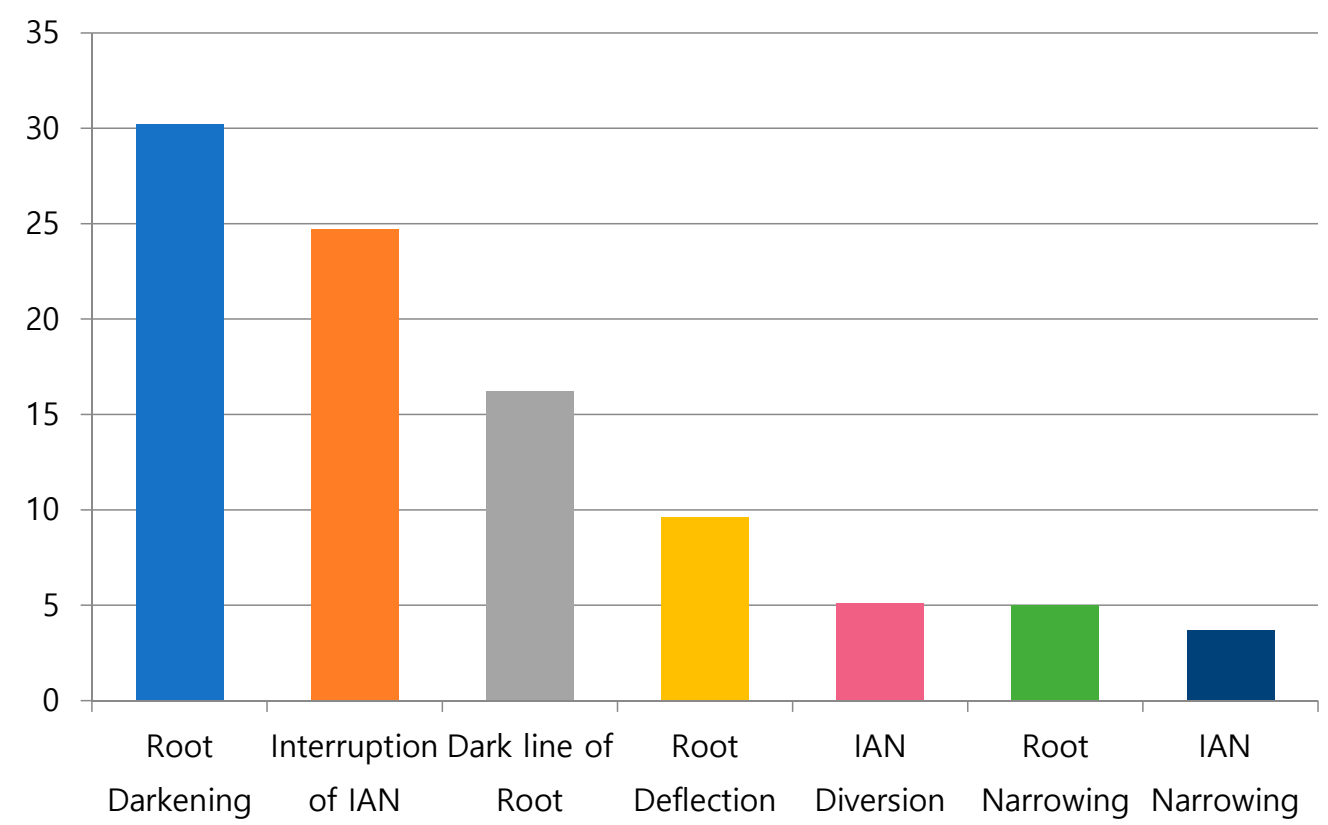

Figure 7. Distributions of panoramic signs: root darkening (30.2\%), interruption of the inferior alveolar nerve (IAN) (24.7\%), dark line of the root (16.2\%), root deflection (9.6\%), IAN diversion (5.1\%), root narrowing (5.0\%), and IAN Narrowing (3.7\%).

\subsection{Relationship between the IAN and the Mandibular Third Molar in CBCT}

In CBCT, 6283 cases (61\%) of the inferior alveolar nerve were actually in contact with the root of the mandibular third molar, which was less than that in the case of panoramic 
contact. Most often, the inferior alveolar nerve was located below the root of the mandibular third molar $(60 \%)$. The second most frequent case of the inferior alveolar nerve was driving to the buccal side of the mandibular third molar (28\%), driving to the lingual side (10\%), and driving between the open roots (1\%), followed by driving between the closed roots $(0.4 \%)$. There were $10 \%$ of cases of the inferior alveolar nerve that appeared to be narrowed due to the roots (Table 4 ).

It was found that there was a correlation between Pell and Gregory classification and the actual contact between the inferior alveolar nerve and the third molar in CBCT. In Class A, $52.4 \%$ were in contact with the inferior alveolar nerve and the third molar in CBCT, 69.4\% in Class B, and $74.3 \%$ in Class C. In Class I, $46.9 \%$ were in contact with the inferior alveolar nerve and the third molar in CBCT; in Class II, 58.2\%; and in Class III, 70.4\% (Table 5).

Table 4. Distribution of inferior alveolar nerve (IAN) pathway in cone beam computed tomography $(\mathrm{CBCT})$.

\begin{tabular}{ccc}
\hline & No. & \% \\
\hline Contact & 6283 & 60.9 \\
Inferior pathway & 6185 & 60.0 \\
Buccal pathway & 2931 & 28.4 \\
Lingual pathway & 1011 & 9.8 \\
Inter-root pathway & 144 & 1.4 \\
Intra-root pathway & 39 & 0.4 \\
Narrowing canal & 1033 & 10.0 \\
\hline
\end{tabular}

Table 5. Association between the Pell and Gregory classification and contact in cone beam computed tomography (CBCT).

\begin{tabular}{|c|c|c|c|c|c|c|c|c|c|}
\hline $\begin{array}{l}\text { P.G. } \\
\text { A, B, } \\
\text { C }\end{array}$ & $\begin{array}{c}\text { Computed } \\
\text { tomography } \\
\text { (CT) Contact } \\
(\%)\end{array}$ & $\begin{array}{c}\text { Without } \\
\text { CT } \\
\text { Contact } \\
(\%)\end{array}$ & Total (\%) & $p$ Value & $\begin{array}{l}\text { P.G. I, } \\
\text { II, III }\end{array}$ & $\underset{\substack{\text { CT } \\
\text { Contact } \\
(\%)}}{ }$ & $\begin{array}{l}\text { Without CT } \\
\text { Contact (\%) }\end{array}$ & Total (\%) & $p$ Value \\
\hline A & $2889(52.4)$ & $2620(47.6)$ & 5509 (100.0) & \multirow{4}{*}{$p<0.001$ * } & I & $565(46.9)$ & $639(53.1)$ & $1204(100.0)$ & \multirow{4}{*}{$p<0.001$ * } \\
\hline B & $2430(69.4)$ & $1073(30.6)$ & $3503(100.0)$ & & II & $3322(58.2)$ & $2382(41.8)$ & $5704(100.0)$ & \\
\hline $\mathrm{C}$ & $964(74.3)$ & $334(25.7)$ & $1298(100.0)$ & & III & 2396 (70.4) & 1006 (29.6) & $3402(100.0)$ & \\
\hline Total & $6283(60.9)$ & $4027(39.1)$ & $10,310(100.0)$ & & Total & $6283(60.9)$ & 4027 (39.1) & $10,310(100.0)$ & \\
\hline
\end{tabular}

* Statistical significance $p<0.05$, Pearson's chi-square test.

In addition, there was a correlation between the Pell and Gregory classification and CBCT when the inferior alveolar nerve was in contact with the third molar root and the inferior alveolar nerve was narrowed. In Class A, 52.4\% were in contact with the inferior alveolar nerve and the mandibular third molar in CBCT, 69.4\% in Class B, and 74.3\% in Class C. In Class I, 46.9\% were in contact with the inferior alveolar nerve and the mandibular third molar in CBCT, $58.2 \%$ in Class II, and 70.4\% in Class III (Table 6).

Table 6. Association between the Pell and Gregory classification and the narrowing canal in cone beam computed tomography (CBCT).

\begin{tabular}{|c|c|c|c|c|c|c|c|c|c|}
\hline $\begin{array}{l}\text { P.G. A, } \\
\text { B, C }\end{array}$ & $\begin{array}{c}\text { Narrowing } \\
\text { Canal }(\%)\end{array}$ & $\begin{array}{c}\text { Without } \\
\text { Narrowing } \\
\text { Canal (\%) }\end{array}$ & Total (\%) & $p$ Value & $\begin{array}{l}\text { P.G. I, } \\
\text { II, III }\end{array}$ & $\begin{array}{c}\text { Narrowing } \\
\text { Canal (\%) }\end{array}$ & $\begin{array}{c}\text { Without } \\
\text { Narrowing } \\
\text { Canal (\%) }\end{array}$ & Total (\%) & $p$ Value \\
\hline $\mathrm{A}$ & $396(7.2)$ & $5113(92.8)$ & $5509(100.0)$ & \multirow{4}{*}{$p<0.001 *$} & $\mathrm{I}$ & $69(5.7)$ & 1135 (94.3) & $1204(100.0)$ & \multirow{4}{*}{$p<0.001$ * } \\
\hline B & 444 (12.7) & 3059 (87.3) & $3503(100.0)$ & & II & $497(8.7)$ & 5207 (91.3) & $5704(100.0)$ & \\
\hline C & 193 (14.9) & 1105 (85.1) & $1298(100.0)$ & & III & 467 (13.7) & $2935(86.3)$ & $3402(100.0)$ & \\
\hline Total & $1033(10.0)$ & $9277(90.0)$ & $10,310(100.0)$ & & Total & $1033(10.0)$ & $9277(90.0)$ & $10,310(100.0)$ & \\
\hline
\end{tabular}

* Statistical significance $p<0.05$, Pearson's chi-square test.

The correlation between the panoramic signs and the actual inferior alveolar nerve contact with the mandibular third molar was investigated using CBCT. Root darkening $\left(p<0.001^{*}\right)$, root deflection $\left(p<0.001^{*}\right)$, interruption of the IAN $\left(p<0.001^{*}\right)$, diversion of the IAN $\left(p<0.001^{*}\right)$, narrowing of the IAN $\left(p<0.001^{*}\right)$, and five other signs were analyzed as having significant correlations (Table 7 ). 
The case where the continuity of the lingual cortical bone disappeared due to the root of the mandibular third molar was investigated in 13.9\%. A dark line at the root apex in panoramic radiography showed a correlation with lingual cortical bone fenestration in CBCT (Table 8).

\subsection{Second and Third Molar Pathology}

The pathological condition of the second and third molars was investigated by examining the medical records and panoramic radiography. $7.3 \%$ was found with pericoronitis around the third molar, and 5.2\% had dental caries on the proximal surface of the second molar. In addition, there was $1.4 \%$ of root resorption of the second molars, and $1.3 \%$ of cystic lesions of the third molars. There was a significant correlation between the incidence of dental caries on the proximal surface of the second molars (Table 9) and the incidence of pericoronitis of the mandibular third molar according to the impact angulation of the third molars (Table 10).

\subsection{Inferior Alveolar Nerve (IAN) Injury}

Of the 4708 patients who underwent surgical extraction, 31 (0.658\%) complained of nerve damage. Among them, 30 patients complained of symptoms of IAN injury, and 1 patient complained of symptoms of lingual nerve injury. In 30 patients with IAN injury, they were administered $50 \mathrm{mg}$ of vitamedin twice a day, $21.96 \mathrm{mg}$ of adenosine triphosphate disodium trihydrate twice a day for 2 weeks, and $30 \mathrm{mg}$ of prednisolone once daily for 12 days with a step down of $5 \mathrm{mg}$ every 2 days. A total of 21 of 30 patients had resolved the symptoms of nerve injury and 9 patients complained of persistent nerve injury. The risk factors of IAN injury were analyzed with impaction pattern, panoramic signs, and CBCT driving pathway except for lingual nerve injury caused by the anesthesia needle. IAN injury was significantly correlated with gender and age (Tables 11 and 12).

Table 7. Association between panoramic signs and contact in cone beam computed tomography (CBCT).

\begin{tabular}{ccccc}
\hline & $\begin{array}{c}\text { CT Contact } \\
\mathbf{( \% )}\end{array}$ & $\begin{array}{c}\text { Without CT } \\
\text { Contact (\%) }\end{array}$ & Total (\%) & $p$ Value \\
\hline Root darkening & $2334(71.8)$ & $876(28.2)$ & $3110(100.0)$ & $p<0.001^{*}$ \\
Without root darkening & $4049(56.2)$ & $3151(43.8)$ & $7200(100.0)$ & \\
Root deflection & $664(67.1)$ & $325(32.9)$ & $989(100.0)$ & $p<0.001$ * \\
Without root deflection & $5619(60.3)$ & $3702(39.7)$ & $9321(100.0)$ & \\
Root narrowing & $332(64.5)$ & $183(35.5)$ & $515(100.0)$ & $p=0.093$ \\
Without root narrowing & $5951(60.8)$ & $3844(39.2)$ & $9795(100.0)$ & \\
Dark line of root & $1021(61.1)$ & $651(38.9)$ & $1672(100.0)$ & $p=0.910$ \\
Without dark line of root & $5262(60.9)$ & $3376(39.1)$ & $8638(100.0)$ & \\
Interruption of IAN & $1944(76.3)$ & $604(23.7)$ & $2548(100.0)$ & $p<0.001$ * \\
Without interruption of IAN & $4339(55.9)$ & $3423(44.1)$ & $7762(100.0)$ & \\
IAN diversion & $474(89.6)$ & $55(10.4)$ & $529(100.0)$ & $p<0.001 *$ \\
Without IAN diversion & $5809(59.4)$ & $3972(40.6)$ & $9781(100.0)$ & \\
IAN narrowing & $319(83.5)$ & $63(16.5)$ & $382(100.0)$ & $p<0.001 *$ \\
Without IAN narrowing & $5964(60.1)$ & $3964(39.9)$ & $9928(100.0)$ & \\
\hline * Statistical significance $p<0.05$, Pearson's chi-square test. & & &
\end{tabular}

Table 8. Association between a dark line of root in panoramic view and lingual cortical bone fenestration in cone beam computed tomography (CBCT).

\begin{tabular}{ccccc}
\hline & $\begin{array}{c}\text { Lingual Cortical Bone } \\
\text { Fenestration (\%) }\end{array}$ & $\begin{array}{c}\text { No Lingual Bone } \\
\text { Fenestration (\%) }\end{array}$ & Total (\%) & $p$ Value \\
\hline $\begin{array}{c}\text { Dark line of root } \\
\text { Without dark } \\
\text { line of root } \\
\text { Total }\end{array}$ & $796(47.6)$ & $876(52.4)$ & $1672(100.0)$ & \\
\hline
\end{tabular}

* Statistical significance $p<0.05$, Pearson's chi-square test. 
Table 9. Association between impaction angulation and proximal caries of the second molar.

\begin{tabular}{ccccc}
\hline & $\begin{array}{c}\text { Proximal Caries } \\
\text { of Second } \\
\text { Molar (\%) }\end{array}$ & $\begin{array}{c}\text { Without Proximal } \\
\text { Caries of Second } \\
\text { Molar (\%) }\end{array}$ & Total (\%) & $p$ Value \\
\hline Horizontal impaction & $195(4.5)$ & $4148(95.5)$ & $4343(100.0)$ & \\
Mesioangular impaction & $251(8.2)$ & $2824(91.8)$ & $3075(100.0)$ & \\
Vertical impaction & $75(3.2)$ & $2290(96.8)$ & $2365(100.0)$ & \\
Distoangular impaction & $5(3.2)$ & $153(96.8)$ & $158(100.0)$ & $p<0.001$ * \\
Inverted impaction & $9(3.2)$ & $271(96.8)$ & $280(100.0)$ & \\
Transverse impaction & $0(0.0)$ & $89(100.0)$ & $89(100.0)$ & \\
Total & $535(5.2)$ & $9775(94.8)$ & $10,310(100.0)$ & \\
* Statistical significance $p<0.05$, Pearson's chi-square test. & &
\end{tabular}

Table 10. Association between impaction angulation and pericoronitis.

\begin{tabular}{ccccc}
\hline & Pericoronitis (\%) & $\begin{array}{c}\text { Without } \\
\text { Pericoronitis (\%) }\end{array}$ & Total (\%) & $p$ Value \\
\hline Horizontal impaction & $297(6.8)$ & $4046(93.2)$ & $4343(100.0)$ & \\
Mesioangular impaction & $175(5.7)$ & $2900(94.3)$ & $3075(100.0)$ & \\
Vertical impaction & $189(8.0)$ & $2176(92.0)$ & $2365(100.0)$ & \\
Distoangular impaction & $38(24.1)$ & $120(75.9)$ & $158(100.0)$ & $p<0.001^{*}$ \\
Inverted impaction & $49(17.5)$ & $231(82.5)$ & $280(100.0)$ & \\
Transverse impaction & $6(6.7)$ & $83(93.3)$ & $89(100.0)$ & \\
Total & $754(7.3)$ & $9556(92.7)$ & $10,310(100.0)$ & \\
\hline
\end{tabular}

* Statistical significance $p<0.05$, Pearson's chi-square test.

In the Pell and Gregory classification, Classes A, B, and C were found to be correlated with nerve injury, and Classes I, II, and III were not correlated (Table 13).

There was a significant correlation with inferior alveolar nerve injury in cases where the roots became dark at the IAN area $(p=0.018)$ and diversion of the inferior alveolar nerve at the root area $(p=0.041)$ (Table 14).

Finally, there was no significant correlation between the driving pathway of the IAN and the IAN injury in CBCT. However, when the IAN showed a lingual pathway and narrowing at the same time, there was a significant correlation with IAN injury (Table 15).

Table 11. Association between gender and numbness.

\begin{tabular}{ccccc}
\hline Gender & Numbness (\%) & Without Numbness (\%) & Total (\%) & $p$ Value \\
\hline Male & $10(0.2)$ & $5374(99.8)$ & $5384(100.0)$ & \\
Female & $20(0.4)$ & $4906(99.6)$ & $4926(100.0)$ & $p=0.038^{*}$ \\
Total & $30(0.3)$ & $10,280(99.7)$ & $10,310(100.0)$ & \\
\hline
\end{tabular}

* Statistical significance $p<0.05$, Pearson's chi-square test.

Table 12. Association between age and numbness.

\begin{tabular}{ccccc}
\hline Age & Numbness (\%) & Without Numbness (\%) & Total (\%) & $p$ Value \\
\hline $10-19$ & $0(0.0)$ & $1879(100.0)$ & $1879(100.0)$ & \\
$20-29$ & $16(0.3)$ & $6046(99.7)$ & $6062(100.0)$ & \\
$30-39$ & $6(0.4)$ & $1387(99.6)$ & $1393(100.0)$ & \\
$40-49$ & $4(0.6)$ & $616(99.4)$ & $620(100.0)$ & \\
$50-59$ & $4(1.8)$ & $221(98.2)$ & $225(100.0)$ & $p<0.001 *$ \\
$60-69$ & $0(0.0)$ & $98(100.0)$ & $98(100.0)$ & \\
$70-79$ & $0(0.0)$ & $30(100.0)$ & $30(100.0)$ & \\
80 & $0(0.0)$ & $3(100.0)$ & $3(100.0)$ & \\
Total & $30(0.3)$ & $10,280(99.7)$ & $1031(100.0)$ & \\
\hline
\end{tabular}

* Statistical significance $p<0.05$, Pearson's chi-square test. 
Table 13. Association between the Pell and Gregory classification (P.G.) and numbness.

\begin{tabular}{|c|c|c|c|c|c|c|c|c|c|}
\hline $\begin{array}{l}\text { P.G.A, } \\
\text { B, C }\end{array}$ & $\underset{(\%)}{\text { Numbness }}$ & $\begin{array}{c}\text { Without } \\
\text { Numbness } \\
(\%)\end{array}$ & Total (\%) & $p$ Value & $\begin{array}{l}\text { P.G. I, } \\
\text { II, III }\end{array}$ & $\underset{(\%)}{\text { Numbness }}$ & $\begin{array}{c}\text { Without } \\
\text { Numbness (\%) }\end{array}$ & Total (\%) & $p$ Value \\
\hline A & $7(0.1)$ & $5502(99.9)$ & $5509(100.0)$ & \multirow{4}{*}{$p=0.004^{*}$} & I & $1(0.1)$ & 1203 (99.9) & $1204(100.0)$ & \multirow{4}{*}{$p=0.189$} \\
\hline B & $16(0.5)$ & 3487 (99.5) & $3503(100.0)$ & & II & $21(0.4)$ & 5683 (99.6) & $5704(100.0)$ & \\
\hline C & $7(0.5)$ & 1291 (99.5) & $1298(100.0)$ & & III & $8(0.2)$ & $3394(99.8)$ & $3402(100.0)$ & \\
\hline Total & $30(0.3)$ & $10,280(99.7)$ & $10,310(100.0)$ & & Total & $30(0.3)$ & $10,280(99.7)$ & $10,310(100.0)$ & \\
\hline
\end{tabular}

* Statistical significance $p<0.05$, Pearson's chi-square test.

Table 14. Association between panoramic signs and inferior alveolar nerve (IAN) injury.

\begin{tabular}{ccccc}
\hline & $\begin{array}{c}\text { Nerve } \\
\text { Injury (\%) }\end{array}$ & $\begin{array}{c}\text { Without } \\
\text { Injury (\%) }\end{array}$ & Total (\%) & $p$ Value \\
\hline Root darkening & $15(0.5)$ & $3095(99.5)$ & $3110(100.0)$ & $p=0.018^{*}$ \\
Without root darkening & $15(0.2)$ & $7185(99.8)$ & $7200(100.0)$ & \\
Root deflection & $4(0.4)$ & $985(99.6)$ & $989(100.0)$ & $p=0.486$ \\
Without root deflection & $26(0.3)$ & $9295(99.7)$ & $9321(100.0)$ & \\
Root narrowing & $3(0.6)$ & $512(99.4)$ & $515(100.0)$ & $p=0.208$ \\
Without root narrowing & $27(0.3)$ & $9768(99.7)$ & $9795(100.0)$ & \\
Dark line of root & $2(0.1)$ & $1670(99.9)$ & $1672(100.0)$ & $p=0.155$ \\
Without dark line of root & $28(0.3)$ & $8610(99.7)$ & $8638(100.0)$ & \\
Interruption of IAN & $9(0.4)$ & $2539(99.6)$ & $2548(100.0)$ & $p=0.501$ \\
Without interruption of IAN & $21(0.3)$ & $7741(99.7)$ & $7762(100.0)$ & \\
IAN diversion & $4(0.8)$ & $525(99.2)$ & $529(100.0)$ & $p=0.041$ * \\
Without IAN diversion & $26(0.3)$ & $9755(99.7)$ & $9781(100.0)$ & \\
IAN narrowing & $1(0.3)$ & $381(99.7)$ & $382(100.0)$ & $p=0.914$ \\
Without IAN narrowing & $29(0.3)$ & $9899(99.7)$ & $9928(100.0)$ & \\
\hline * Statistical significance $p<0.05$, Pearson's chi-square test. & & &
\end{tabular}

* Statistical significance $p<0.05$, Pearson's chi-square test.

Table 15. Risk factors of inferior alveolar nerve (IAN) injury in cone beam computed tomography (CBCT).

\begin{tabular}{ccccc}
\hline Risk Factors & Injury (\%) & Without Injury (\%) & Total (\%) & $p$ Value \\
\hline Both lingual pathway & $24(3.8)$ & $605(96.0)$ & $629(100.0)$ & \\
and IAN narrowing & $0(0.0)$ & $592(100.0)$ & $592(100.0)$ & $p<0.001^{*}$ \\
Only lingual pathway & $3(0.0)$ & $8682(100.0)$ & $8685(100.0)$ & \\
Only IAN narrowing & $3(0.7)$ & $401(99.3)$ & $404(100.0)$ & \\
No lingual pathway or & $30(0.3)$ & $10,280(99.7)$ & $10,310(100.0)$ & \\
$\quad$ IAN narrowing & Total & &
\end{tabular}

* Statistical significance $p<0.05$, Pearson's chi-square test.

\section{Discussion}

Extraction of the mandibular third molar is the most commonly performed surgical procedure in oral and maxillofacial surgery. IAN injury can cause a lot of discomfort to the patient and lower the quality of life [35]. However, there are still not many studies on the relationship between the inferior alveolar nerve and mandibular third molars in populations.

This study was to evaluate the pattern of mandibular third molar impaction in Korea and to evaluate the risk factors of inferior alveolar nerve damage that may occur during extraction. Prevalence of third molar impaction is reported to range from $30.3 \%$ to $68.6 \%$ [2-6]. The prevalence of impaction could not be determined in this study as it was intended for patients with impacted mandibular third molars. The gender difference regarding the impacted mandibular third molar varied from study to study. Previous studies showed that women have a higher prevalence of impaction $[6,36]$ and another study showed that men have a higher prevalence of impaction [37]. Impaction of the third molar was $52.1 \%$ in men, and the average age was 33.5 years. Patients 10 to 39 years old accounted for $88.4 \%$ of this study.

The impaction pattern was varied according to the angulation. Most of studies showed that mesial angulation $[6,38-41]$ and vertical impaction $[42,43]$ occur frequently. In this 
study, horizontal angulation was most popular. CBCT is taken when there is a suspicion of contact between the IAN and the mandibular third molar in panoramic radiographs, or when the third molars are completely impacted. Since the subject of this study was patients who underwent $\mathrm{CBCT}$, this might have affected the outcome as patients with a mandibular third molar impacted by a vertical or a mesial impaction, which is relatively far from the IAN, were not included.

According to the Pell and Gregory classification, the most prevalent was Class IIA $(30.0 \%)$, followed by Class IIB (19.3\%). This is consistent with previous results [1,14,44]. Monaco [45] reported that Class A (56.2\%) and Class II (63\%) were the most common among Italians, and Blondeau [46] and Almendros-Marques [43] reported that Class IIB was the most common. It can be seen that Koreans do not differ in the degree and distribution of impaction from different races. In addition, it was found that the depth of the impaction increased as age increased. This suggests that patients with low impacted mandibular third molars remove their teeth at a relatively young age, so as the age increases, deep impacted mandibular third molars, which are difficult to extract, are present at a higher rate.

Panoramic radiographic signs were reported to occur at a low frequency of $0.1 \% \sim 3.3 \%$ in the study by Rood and Shehab [20]. Sedaghatfar et al. [11] reported the occurrence at a rate of $11.8-35.9 \%$, similar to this study. This difference is thought to be due to the difference between observers in determining the symptoms, as the evaluation of the signs in the panoramic radiograph is not standardized. In addition, the subjects of this study had panoramic radiographs of the mandibular third molar and inferior alveolar nerves that were in contact with each other, so it is thought that the incidence of signs was higher than that of a completely randomized study.

In CBCT, the contact between the mandibular third molar and the inferior alveolar nerve was observed in $61 \%$, which was less than the cases with contact on the panoramic radiograph $(88.67 \%)$. This means that it was not possible to accurately determine whether the mandibular third molar and the inferior alveolar nerve were actually in contact with the panoramic radiograph. There was a significant correlation between the Pell and Gregory classification, the contact between the mandibular third molar and the IAN in CBCT, and the narrowing of the IAN in CBCT. This means that the deeper the degree of impaction of the mandibular third molar, the closer it was to the IAN. As for the signs on the panoramic radiograph, there was a correlation between the actual contact between the mandibular third molar and the IAN in CBCT, except when the root was narrowed and there was a dark line at the root apex [47-49].

There was a correlation between the disappearance of the continuity of the lingual cortical bone at the root of the mandibular third molar and the dark line at the root apex. Dark lines were observed in $55.7 \%$ of cases with lingual cortical bone perforation, and were absent in $44.3 \%$ of cases with lingual cortical bone perforation. In the literature examining the dark area of the root and lingual cortical bone perforation, it was suggested that the dark area showed proximity to the IAN rather than the lingual cortical bone perforation [50]. It is believed that this is caused by not distinguishing from dark lines when irradiating the dark area. If the root is in the lingual cortical bone, it is thought that the presence of the periodontal ligament in the dense cortical bone and the perforated area of the cortical bone appear as dark lines. The possibility of root fracture occurring during extraction increases, and the fractured root may fall into the submandibular space, so care should be taken during extraction. It would be useful if we could predict the existence of roots in the lingual cortical bone only with panoramic radiographs, not CBCT.

In the case of proximal dental caries $46.9 \%$ had mesial impaction and $36.4 \%$ had horizontal impaction. This is consistent with other studies that stated that the mesial and horizontal impaction of the third molar accounts for most of the proximal caries of the second molar [51,52]. In addition, when examining the relationship between pericoronitis and impaction angulation in various studies, it was reported that vertical impaction was the most common, followed by mesial impaction, and bone loss was most observed in mesial impaction [53,54]. In this study, horizontal impaction was the most common (39.4\%), 
followed by vertical impaction (25.0\%) and mesial impaction (23.2\%). Out of 158 distal impactions, 38 cases had pericoronitis, showing a high morbidity rate of about $24 \%$.

The incidence of IAN injury was $0.637 \%$, which is similar to or lower than that reported in other studies [9-15]. Of the 30 patients with IAN injury, there was a statistically significant correlation with gender $(p=0.038)$, with risk of nerve damage being higher in women than men. Other studies reported that there was no correlation between gender and nerve injury [31], but many studies have reported that women have a higher risk of nerve injury $[23,24,55]$. In addition, there was a significant correlation between age and IAN injury. It can be seen that the possibility IAN injury increases with age. There was also literature reporting that the age and risk of nerve injury were not correlated [55,56]. However, many studies have shown that the risk of IAN injury increases in those over 25 years of age, and age is a risk factor for nerve injury [15,23,57-61]. Age-related changes such as a decrease in bone elasticity, an increase in the occurrence of hypercementosis, and an increase in the amount of bone removal are thought to be the major causes of the increase in the difficulty of surgery. There are studies suggesting a relationship between the depth of impaction and the incidence of IAN injury $[9,13,23,30,55,56,58,60]$, and a study suggesting no relationship [31]. In the present study, it was found that there is a relationship between the depth of impaction and the incidence of IAN injury. Naturally, the deeper the impaction depth, the closer it is to the inferior alveolar nerve, and therefore, the probability of nerve injury is thought to increase. No significant correlation was found between the signs of panoramic radiographs and the incidence of IAN injury. This result is similar to most studies $[9,11,20,23,26,28,31]$. It is considered that the prediction of IAN injury is inadequate, as a panoramic radiograph sign has low sensitivity and high specificity. In this study, among 30 patients with IAN injury, 24 showed that the IAN was driven to the lingual side of the mandibular third molar root in CBCT, and at the same time, a narrowing of the IAN was observed. When these two features are observed at the same time, it can be said that the incidence of IAN injury increases. The narrowed IAN in CBCT and the lingual pathway of the IAN is consistent with other studies that suggested increased risk of IAN injury $[27,32,62,63]$. The narrowing of the IAN canal means that the distance between the root of the mandibular third molar and the IAN canal is less. Clinically, when the mandibular third molar is extracted, most of the instrumentation is performed on the buccal side. Because of this, there are many cases where the tooth comes out while applying force in the lingual direction. Due to this effect, it is thought that the lingual movement and narrowing of the IAN cause IAN injury during extraction. This is thought to be a good factor in predicting the occurrence of nerve injury.

This study examined the impaction pattern and the risk factors affecting injury to the IAN in Koreans. The study had several limitations. First, it cannot be concluded that the study reflects the overall characteristics of Koreans, as it was short-term research by a single institution. Second, the study only included patients who underwent panoramic radiography and $\mathrm{CBCT}$, instead of using random target collection. Unlike other studies, this study was intended for patients with impacted mandibular third molars and also for patients who underwent CBCT, following a suspicion of an impacted third mandibular molar being in contact with the inferior alveolar nerve. For this reason, there are limitations to consider when interpreting the results; therefore, the study cannot be generalized to the Korean population with impacted third mandibular molars. Third, the symptoms of patients with an IAN injury could not be described in detail due to the incomplete medical records and the loss of follow-up. As in other studies, it is necessary to classify the symptoms of temporary and permanent nerve injury and investigate the intensity of the symptoms.

The data and results of this study can be used to set the direction of future research. With more complementary studies, we can set the criteria for classification of the mandibular third molar in Koreans, analyze the third molar conveniently and quickly using artificial intelligence, and further create programs that can determine the degree of difficulty in the extraction, the possibility of injury to the IAN, and the possibility of complications. 


\section{Conclusions}

In this study, Class IIA, IIB were dominant in the impaction pattern of the mandibular third molar. In addition, when there was a dark line at the root apex on the panoramic radiograph, it was found that the root of the mandibular third molar was often located in the lingual cortical bone. It was found that when the narrowing of the IAN and the lingual driving pathway of the IAN appeared simultaneously in CBCT, the risk of an IAN injury was high. These two factors appear together, and clinicians should explain the possibility of IAN injury to the patient and the need to extract more carefully.

Author Contributions: Conceptualization, S.Y.M.; methodology, S.Y.M.; software, S.Y.M. and H.J.K. (Hyo Joon Kim); validation, S.Y.M., H.J.K. (Hee Jin Kim), and H.J.K. (Hyo Joon Kim); formal analysis, S.Y.M. and H.J.K. (Hyo Joon Kim); investigation Y.J.J., J.S.C., H.J.K. (Hee Jin Kim) and H.J.K. (Hyo Joon Kim); resources, S.Y.M.; data curation, S.Y.M., Y.J.J., J.S.C. and H.J.K. (Hee Jin Kim); writing—original draft preparation, H.J.K. (Hee Jin Kim); writing-review and editing, H.J.K. (Hee Jin Kim) and S.Y.M.; visualization, S.Y.M.; supervision, J.K. and S.Y.M.; project administration, S.Y.M.; funding acquisition, S.Y.M. All authors have read and agreed to the published version of the manuscript.

Funding: This study was supported by the research fund from Chosun University, 2020.

Institutional Review Board Statement: The study was conducted according to the guidelines of the Declaration of Helsinki, and approved by the Institutional Review Board of Chosun university dental hospital (CUDHIRB 1902006R01).

Informed Consent Statement: Informed consent was obtained from all subjects involved in the study.

Data Availability Statement: No new data were created or analyzed in this study. Data sharing is not applicable to this article.

Conflicts of Interest: The authors declare no conflict of interest.

\section{References}

1. Al-Dajani, M.; Abouonq, A.O.; Almohammadi, T.A.; Alruwaili, M.K.; Alswilem, R.O.; Alzoubi, I.A. A cohort study of the patterns of third molar impaction in panoramic radiographs in Saudi population. Open Dent. J. 2017, 11, 648. [CrossRef] [PubMed]

2. Schersten, E.; Lysell, L.; Rohlin, M. Prevalence of impacted third molars in dental students. Swed. Dent. J. 1989, 13, 7-13. [PubMed]

3. Yilmaz, S.; Adisen, M.Z.; Misirlioglu, M.; Yorubulut, S. Assessment of third molar impaction pattern and associated clinical symptoms in a central anatolian turkish population. Med. Princ. Pract. 2016, 25, 169-175. [CrossRef] [PubMed]

4. Gisakis, I.G.; Palamidakis, F.D.; Farmakis, E.T.R.; Kamberos, G.; Kamberos, S. Prevalence of impacted teeth in a Greek population. J. Investig. Clin. Dent. 2011, 2, 102-109. [CrossRef]

5. Kruger, E.; Thomson, W.M.; Konthasinghe, P. Third molar outcomes from age 18 to 26: Findings from a population-based New Zealand longitudinal study. Oral Surg. Oral Med. Oral Pathol. Oral Radiol. Endodontol. 2001, 92, 150-155. [CrossRef]

6. Quek, S.; Tay, C.; Tay, K.; Toh, S.; Lim, K. Pattern of third molar impaction in a Singapore Chinese population: A retrospective radiographic survey. Int. J. Oral Maxillofac. Surg. 2003, 32, 548-552. [CrossRef]

7. Umar, G.; Bryant, C.; Obisesan, O.; Rood, J. Correlation of the radiological predictive factors of inferior alveolar nerve injury with cone beam computed tomography findings. Oral Surg. 2010, 3, 72-82. [CrossRef]

8. Tay, A.; Zuniga, J.R. Clinical characteristics of trigeminal nerve injury referrals to a university centre. Int. J. Oral Maxillofac. Surg. 2007, 36, 922-927. [CrossRef]

9. Szalma, J.; Lempel, E.; Jeges, S.; Szabó, G.; Olasz, L. The prognostic value of panoramic radiography of inferior alveolar nerve damage after mandibular third molar removal: Retrospective study of 400 cases. Oral Surg. Oral Med. Oral Pathol. Oral Radiol. Endodontol. 2010, 109, 294-302. [CrossRef]

10. Susarla, S.M.; Dodson, T.B. Risk factors for third molar extraction difficulty. J. Oral Maxillofac. Surg. 2004, 62, 1363-1371. [CrossRef]

11. Sedaghatfar, M.; August, M.A.; Dodson, T.B. Panoramic radiographic findings as predictors of inferior alveolar nerve exposure following third molar extraction. J. Oral Maxillofac. Surg. 2005, 63, 3-7. [CrossRef] [PubMed]

12. Kjølle, G.K.; Bjørnland, T. Low risk of neurosensory dysfunction after mandibular third molar surgery in patients less than 30 years of age. A prospective study following removal of 1220 mandibular third molars. Oral Surg. Oral Med. Oral Pathol. Oral Radiol. 2013, 116, 411-417. [CrossRef] [PubMed]

13. Jerjes, W.; Upile, T.; Shah, P.; Nhembe, F.; Gudka, D.; Kafas, P.; McCarthy, E.; Abbas, S.; Patel, S.; Hamdoon, Z. Risk factors associated with injury to the inferior alveolar and lingual nerves following third molar surgery-Revisited. Oral Surg. Oral Med. Oral Pathol. Oral Radiol. Endodontol. 2010, 109, 335-345. [CrossRef] [PubMed] 
14. Queral-Godoy, E.; Valmaseda-Castellón, E.; Berini-Aytés, L.; Gay-Escoda, C. Incidence and evolution of inferior alveolar nerve lesions following lower third molar extraction. Oral Surg. Oral Med. Oral Pathol. Oral Radiol. Endodontol. 2005, 99, $259-264$. [CrossRef] [PubMed]

15. Blondeau, F.; Daniel, N.G. Extraction of impacted mandibular third molars: Postoperative complications and their risk factors. J. Can. Dent. Assoc. 2007, 73, 325-325e. [PubMed]

16. Haug, R.H.; Perrott, D.H.; Gonzalez, M.L.; Talwar, R.M. The American Association of Oral and Maxillofacial Surgeons age-related third molar study. J. Oral Maxillofac. Surg. 2005, 63, 1106-1114. [CrossRef]

17. Baqain, Z.H.; Karaky, A.A.; Sawair, F.; Khaisat, A.; Duaibis, R.; Rajab, L.D. Frequency estimates and risk factors for postoperative morbidity after third molar removal: A prospective cohort study. J. Oral Maxillofac. Surg. 2008, 66, 2276-2283. [CrossRef]

18. Smith, W. The relative risk of neurosensory deficit following removal of mandibular third molar teeth: The influence of radiography and surgical technique. Oral Surg. Oral Med. Oral Pathol. Oral Radiol. 2013, 115, 18-24. [CrossRef]

19. Smith, A.C.; Barry, S.E.; Chiong, A.Y.; Hadzakis, D.; Kha, S.L.; Mok, S.C.; Sable, D.L. Inferior alveolar nerve demage following removal of mandibular third molar teeth. A prospective study using panoramic radiography. Aust. Dent. J. 1997, 42, 149-152. [CrossRef]

20. Rood, J.; Shehab, B.N. The radiological prediction of inferior alveolar nerve injury during third molar surgery. Br. J. Oral Maxillofac. Surg. 1990, 28, 20-25. [CrossRef]

21. de Melo Albert, D.G.; Gomes, A.C.A.; do Egito Vasconcelos, B.C.; e Silva, E.D.d.O.; Holanda, G.Z. Comparison of orthopantomographs and conventional tomography images for assessing the relationship between impacted lower third molars and the mandibular canal. J. Oral Maxillofac. Surg. 2006, 64, 1030-1037. [CrossRef] [PubMed]

22. Tantanapornkul, W.; Okouchi, K.; Fujiwara, Y.; Yamashiro, M.; Maruoka, Y.; Ohbayashi, N.; Kurabayashi, T. A comparative study of cone-beam computed tomography and conventional panoramic radiography in assessing the topographic relationship between the mandibular canal and impacted third molars. Oral Surg. Oral Med. Oral Pathol. Oral Radiol. Endodontol. 2007, 103, 253-259. [CrossRef] [PubMed]

23. Valmaseda-Castellón, E.; Berini-Aytés, L.; Gay-Escoda, C. Inferior alveolar nerve damage after lower third molar surgical extraction: A prospective study of 1117 surgical extractions. Oral Surg. Oral Med. Oral Pathol. Oral Radiol. Endodontol. 2001, 92, 377-383. [CrossRef] [PubMed]

24. Nakagawa, Y.; Ishii, H.; Nomura, Y.; Watanabe, N.Y.; Hoshiba, D.; Kobayashi, K.; Ishibashi, K. Third molar position: Reliability of panoramic radiography. J. Oral Maxillofac. Surg. 2007, 65, 1303-1308. [CrossRef] [PubMed]

25. Nakamori, K.; Fujiwara, K.; Miyazaki, A.; Tomihara, K.; Tsuji, M.; Nakai, M.; Michifuri, Y.; Suzuki, R.; Komai, K.; Shimanishi, M. Clinical assessment of the relationship between the third molar and the inferior alveolar canal using panoramic images and computed tomography. J. Oral Maxillofac. Surg. 2008, 66, 2308-2313. [CrossRef]

26. Gomes, A.C.A.; do Egito Vasconcelos, B.C.; de Oliveira Silva, E.D.; de França Caldas, A., Jr.; Neto, I.C.P. Sensitivity and specificity of pantomography to predict inferior alveolar nerve damage during extraction of impacted lower third molars. J. Oral Maxillofac. Surg. 2008, 66, 256-259. [CrossRef] [PubMed]

27. Jhamb, A.; Dolas, R.S.; Pandilwar, P.K.; Mohanty, S. Comparative efficacy of spiral computed tomography and orthopantomography in preoperative detection of relation of inferior alveolar neurovascular bundle to the impacted mandibular third molar. J. Oral Maxillofac. Surg. 2009, 67, 58-66. [CrossRef]

28. Atieh, M.A. Diagnostic accuracy of panoramic radiography in determining relationship between inferior alveolar nerve and mandibular third molar. J. Oral Maxillofac. Surg. 2010, 68, 74-82. [CrossRef]

29. Leung, Y.Y.; Cheung, L.K. Correlation of radiographic signs, inferior dental nerve exposure, and deficit in third molar surgery. J. Oral Maxillofac. Surg. 2011, 69, 1873-1879. [CrossRef]

30. Kim, J.-W.; Cha, I.-H.; Kim, S.-J.; Kim, M.-R. Which risk factors are associated with neurosensory deficits of inferior alveolar nerve after mandibular third molar extraction? J. Oral Maxillofac. Surg. 2012, 70, 2508-2514. [CrossRef]

31. Pippi, R.; Santoro, M. A multivariate statistical analysis on variables affecting inferior alveolar nerve damage during third molar surgery. Br. Dent. J. 2015, 219, E3. [CrossRef] [PubMed]

32. Ghaeminia, H.; Meijer, G.; Soehardi, A.; Borstlap, W.; Mulder, J.; Bergé, S. Position of the impacted third molar in relation to the mandibular canal. Diagnostic accuracy of cone beam computed tomography compared with panoramic radiography. Int. J. Oral Maxillofac. Surg. 2009, 38, 964-971. [CrossRef] [PubMed]

33. Pell, G.J. Impacted mandibular third molars: Classification and modified techniques for removal. Dent Digest 1933, $39,330-338$.

34. Winter, G.B. Impacted Mandibular Third Molar; American Medical Book Company: St. Louis, MO, USA, 1926; pp. $241-279$.

35. Cakir, M.; Karaca, İ.R.; Peker, E.; Ogütlü, F. Effects of inferior alveolar nerve neurosensory deficits on quality of life. Niger. J. Clin. Pract. 2018, 21, 206.

36. Hugoson, A. The prevalence of third molars in a Swedish population: An epidemiological study. Community Dent. Health 1988, 5, 121-138.

37. Bozzatello, J. Relationship between craniofacial architecture and retained lower third molar. Its' symptomatology. Rev. Fac. Cienc. Med. (Cordoba, Argent.) 2006, 63, 38-42.

38. Meisami, T.; Sojat, A.; Sandor, G.; Lawrence, H.; Clokie, C. Impacted third molars and risk of angle fracture. Int. J. Oral Maxillofac. Surg. 2002, 31, 140-144. [CrossRef]

39. Bui, C.H.; Seldin, E.B.; Dodson, T.B. Types, frequencies, and risk factors for complications after third molar extraction. J. Oral Maxillofac. Surg. 2003, 61, 1379-1389. [CrossRef] 
40. Unwerawattana, W. Common symptoms and type of impacted molar tooth in King Chulalongkorn Memorial Hospital. J. Med. Assoc. Thail. Chotmaihet Thangphaet 2006, 89, S134-S139.

41. Chaparro-Avendaño, A.; Pérez-García, S.; Valmaseda-Castellón, E.; Berini-Aytés, L.; Gay-Escoda, C. Morbidity of third molar extraction in patients between 12 and 18 years of age. Med. Oral Patol. Oral Cirugía Bucal 2005, 10, 422-431.

42. Bataineh, A.B.; Albashaireh, Z.S.; Hazza'a, A.M. The surgical removal of mandibular third molars: A study in decision making. Quintessence Int. 2002, 33, 613-617. [PubMed]

43. Almendros-Marqués, N.; Berini-Aytés, L.; Gay-Escoda, C. Influence of lower third molar position on the incidence of preoperative complications. Oral Surg. Oral Med. Oral Pathol. Oral Radiol. Endodontol. 2006, 102, 725-732. [CrossRef] [PubMed]

44. Bishara, S.E.; Ortho, D. Impacted maxillary canines: A review. Am. J. Orthod. Dentofac. Orthop. 1992, 101, 159-171. [CrossRef]

45. Monaco, G.; Montevecchi, M.; Bonetti, G.A.; Gatto, M.R.A.; Checchi, L. Reliability of panoramic radiography in evaluating the topographic relationship between the mandibular canal and impacted third molars. J. Am. Dent. Assoc. 2004, 135, 312-318. [CrossRef]

46. Rajasuo, A.; Murtomaa, H.; Meurman, J.H. Comparison of the clinical status of third molars in young men in 1949 and in 1990. Oral Surg. Oral Med. Oral Pathol. 1993, 76, 694-698. [CrossRef]

47. Kipp, D.P.; Goldstein, B.H.; Weiss, W.W. Dysesthesia after mandibular third molar surgery: A retrospective study and analysis of 1,377 surgical procedures. J. Am. Dent. Assoc. 1980, 100, 185-192. [CrossRef]

48. Littner, M.; Kaffe, I.; Tamse, A.; Dicapua, P. Relationship between the apices of the lower molars and mandibular canal-A radiographic study. Oral Surg. Oral Med. Oral Pathol. 1986, 62, 595-602. [CrossRef]

49. Rud, J. Third molar surgery: Relationship of root to mandibular canal and injuries to inferior dental nerve. Tandlaegebladet 1983, 87, 619-631.

50. Szalma, J.; Vajta, L.; Lempel, E.; Jeges, S.; Olasz, L. Darkening of third molar roots on panoramic radiographs: Is it really predominantly thinning of the lingual cortex? Int. J. Oral Maxillofac. Surg. 2013, 42, 483-488. [CrossRef]

51. Ozeç, I.; Hergüner, S.S.; Taşdemir, U.; Ezirganli, S.; Göktolga, G. Prevalence and factors affecting the formation of second molar distal caries in a Turkish population. Int. J. Oral Maxillofac. Surg. 2009, 38, 1279-1282. [CrossRef]

52. Claudia, A.; Barbu, H.M.; Adi, L.; Gultekin, A.; Reiser, V.; Gultekin, P.; Mijiritsky, E. Relationship between third mandibular molar angulation and distal cervical caries in the second molar. J. Craniofacial Surg. 2018, 29, 2267-2271. [CrossRef] [PubMed]

53. Halverson, B.A.; Anderson, W.H., III. The mandibular third molar position as a predictive criteria for risk for pericoronitis: A retrospective study. Mil. Med. 1992, 157, 142-145. [CrossRef] [PubMed]

54. Hazza'a, A.M.; Bataineh, A.B.; Odat, A.-A. Angulation of mandibular third molars as a predictive factor for pericoronitis. J. Contemp. Dent. Pract. 2009, 10, 51-58. [PubMed]

55. Hasegawa, T.; Ri, S.; Umeda, M.; Komori, T. Multivariate relationships among risk factors and hypoesthesia of the lower lip after extraction of the mandibular third molar. Oral Surg. Oral Med. Oral Pathol. Oral Radiol. Endodontol. 2011, 111, e1-e7. [CrossRef]

56. Jerjes, W.; Swinson, B.; Moles, D.; El-Maaytah, M.; Banu, B.; Upile, T.; Kumar, M.; Al Khawalde, M.; Vourvachis, M.; Hadi, H. Permanent sensory nerve impairment following third molar surgery: A prospective study. Oral Surg. Oral Med. Oral Pathol. Oral Radiol. Endodontol. 2006, 102, e1-e7. [CrossRef]

57. Lyons, C.J.; Bruce, R.A.; Frederickson, G.C.; Small, G.S. Age of patients and morbidity associated with mandibular third molar surgery. J. Am. Dent. Assoc. 1980, 101, 240-245. [CrossRef]

58. Tay, A.B.G.; Go, W.S. Effect of exposed inferior alveolar neurovascular bundle during surgical removal of impacted lower third molars. J. Oral Maxillofac. Surg. 2004, 62, 592-600. [CrossRef]

59. Chiapasco, M.; Crescentini, M.; Romanoni, G. Germectomy or delayed removal of mandibular impacted third molars: The relationship between age and incidence of complications. J. Oral Maxillofac. Surg. 1995, 53, 418-422. [CrossRef]

60. Chuang, S.-K.; Perrott, D.H.; Susarla, S.M.; Dodson, T.B. Age as a risk factor for third molar surgery complications. J. Oral Maxillofac. Surg. 2007, 65, 1685-1692. [CrossRef]

61. Black, C. Sensory impairment following lower third molar surgery: A prospective study in New Zealand. N. Z. Dent. J. 1997, 93, 68-71.

62. Eyrich, G.; Seifert, B.; Matthews, F.; Matthiessen, U.; Heusser, C.K.; Kruse, A.L.; Obwegeser, J.A.; Lübbers, H.-T. 3-Dimensional imaging for lower third molars: Is there an implication for surgical removal? J. Oral Maxillofac. Surg. 2011, 69, $1867-1872$. [CrossRef] [PubMed]

63. Maegawa, H.; Sano, K.; Kitagawa, Y.; Ogasawara, T.; Miyauchi, K.; Sekine, J.; Inokuchi, T. Preoperative assessment of the relationship between the mandibular third molar and the mandibular canal by axial computed tomography with coronal and sagittal reconstruction. Oral Surg. Oral Med. Oral Pathol. Oral Radiol. Endodontol. 2003, 96, 639-646. [CrossRef] 